\title{
The relation between physical function and musculoskeletal pain in overweight/obese people
}

\author{
Tomomi Hasegawa ${ }^{1}$, Tatsunori Ikemoto ${ }^{1,2}$, Masayuki Inoue ${ }^{1}$, \\ Setsuko Yamaguchi ${ }^{1}$, Takahiro Ushida ${ }^{1,2}$, Eiji Shibata ${ }^{3}$, \\ and Fumio Kobayashi ${ }^{3}$ \\ 'Institute of Physical Fitness, Sports Medicine and Rehabilitation, Aichi Medical University \\ ${ }^{2}$ Multidisciplinary Pain Center, Aichi Medical University \\ ${ }^{3}$ Department of Health and Psychosocial Medicine, School of Medicine, Aichi Medical University
}

\begin{abstract}
The aim of this study was to investigate the features of overweight or obese individuals with a BMI $>25 \mathrm{~kg} / \mathrm{m}^{2}$ who complained of low back pain, knee pain, and neck stiffness. The subjects comprised 88 overweight or obese individuals who were divided into a symptomatic group and an asymptomatic group prior to the weight-loss intervention in order to compare several parameters of each group. Symptomatic patients were divided into groups of subjects whose symptoms did or did not improve as a result of the 6 -month weight-loss intervention. Changes in the test parameters from before and after the intervention were compared between the two groups. The results revealed no differences in any parameters between the two groups (symptomatic and asymptomatic) at baseline in neck stiffness or low back pain. However, for knee pain, the maximal oxygen uptake $\left(\mathrm{VO}_{2} \max \right)$ was significantly lower in the symptomatic group than in the asymptomatic group $(p<0.01)$. Furthermore, the weight-loss intervention revealed a significant increase in $\mathrm{VO}_{2}$ max in the "improved" group compared to the "no change" group $(p<0.05)$. The study results showed that both weight loss and the acquisition of aerobic capacity were important in relieving knee pain in overweight or obese individuals.
\end{abstract}

Keywords

Aerobic capacity; Knee pain

Received: 5 December 2013

Accepted: 17 January 2014

1

PAIN RESEARCH Vol.29 2014 


\title{
過体重・肥満者の運動器疼痛と身体機能の関係
}

\author{
長谷川 共美 1 / 池本 竜則 1,2 /井上 雅之 $1 /$ 山口 節子 1 \\ 牛田 享宏 1,2 /柴田 英治 $3 /$ 小林 章雄 3 \\ 1 愛知医科大学 運動療育センター \\ 2 愛知医科大学 学際的痛みセンター \\ 3 愛知医科大学 衛生学教室
}

\section{はじめに}

高カロリー食品の過剩摂取や運動不足など, 現代人の生活習慣を反映した状態である肥満 は, メタボリック症候群などの代謝・循環器異 常 23), 癌 23), 認知症 29) の他に滕痛や澒部痛, 腰痛などの運動器疼痛疾患に影響を及ぼすこと が指摘されてきている13,24)。例えば，過体重が 膝痛のリスク因子であることは，様々な報告か ら証明されており $1,7,13,21,24)$, 減量行為そのもの が過体重者に対する膝 OA の治療ガイドライ ンとして強く推奨されている10)。また肥満と 腰痛との関係についての報告 1,8$)$ や, 近年の双 子研究についてのレビューでは両者の関連が指 摘されている4)。このように肥満は, 運動器疼 痛のリスク要因と考えられているが, 運動器疼 痛症状に関与するメカニズムについては，過体 重や肥満そのものが筋骨格系の物理的過負担 になっており5,25,26), さらに脂肪代謝が神経障 害を介して疼痛症状に影響を与えている可能 性 $20,27,28)$ ，また肥満に伴う慢性炎症が関与する 可能性 $24 ）$ などが指摘されているが，いまだ不 明な点も多い。

そこで今回, $\mathrm{BMI} \geqq 25$ の過体重・肥満者に対 して運動指導と栄養指導を併用した 6 力月の減 量プログラムを行い，わが国において有訴率の 高い自覚症状である ${ }^{9)}$, 肩こり, 腰痛, 滕痛の
3 つの運動器疼痛症状について, 減量開始前ま たは減量介入後の身体計測值, 生理機能測定 值, 血液生化学検查, 1 日歩数, 食事摂取力口 リーなどの項目から，各症状に関与する因子を 検討した。

\section{対象・方法}

対象は一般広告により募った減量教室参加希 望者のうち, 事前のスクリーニング検查で運動 禁忌となる重篤な合併症がなく, 医師からの運 動制限がないことを確認した成人男女 95 名の 中で, $B M I \geqq 25$ の過体重・肥満者 88 名（女性 $93 \%$, 体重 $72.9 \pm 12.6$, BMI $29.9 \pm 4.2$, 体脂 肪率 $32.2 \pm 5.5)$ を対象とした。

倫理的考慮は参加者から同意を得るととも に, 本学倫理委員会の承認(No.12-124)を得た。 減量プログラム：減量プログラムは運動指導 と栄養指導を併用した 6 カ月間のプログラム で, 参加者本人の減量希望を基に, 月 $2 \mathrm{~kg}$ ペースで最大 $12 \mathrm{~kg}$ の安全な目標体重を検討 し，提示した。但し希望体重が理想体重である BMI 22 を下回る場合は BMI 22 を目標体重と した。これにより 1 日当たりの減量エネルギー を算出し，運動によるエネルギー消費分と栄養 による摂取エネルギー制限分をそれぞれ決定し 
Table 1 Comparison of each test parameter at baseline by the presence or absence of subjective musculoskeletal symptoms

\begin{tabular}{|c|c|c|c|c|c|c|}
\hline \multirow{2}{*}{ Parameters } & \multicolumn{2}{|c|}{ Knee pain } & \multicolumn{2}{|c|}{ Low back pain } & \multicolumn{2}{|c|}{ Neck stiffness } \\
\hline & Presence (25) & Absence (63) & Presence (28) & Absence (60) & Presence (41) & Absence (47) \\
\hline Age (y.o.) & $55.1 \pm 12.2$ & $47.9 \pm 12.1^{* *}$ & $52 \pm 10.5$ & $49 \pm 13.3$ & $50.8 \pm 11.9$ & $49.2 \pm 13.0$ \\
\hline Weight (kg) & $74.2 \pm 12.7$ & $72.4 \pm 12.7$ & $71.3 \pm 10.7$ & $73.6 \pm 13.5$ & $72.3 \pm 13.4$ & $73.4 \pm 12.0$ \\
\hline $\operatorname{BMI}\left(\mathrm{kg} / \mathrm{m}^{2}\right)$ & $30.5 \pm 4.6$ & $29.7 \pm 4.1$ & $29.2 \pm 3.6$ & $30.3 \pm 4.5$ & $29.7 \pm 4.1$ & $30.1 \pm 4.4$ \\
\hline$\% \mathrm{FAT}(\%)$ & $32.4 \pm 4.8$ & $32.2 \pm 5.8$ & $32.5 \pm 4.7$ & $32.1 \pm 5.8$ & $31.8 \pm 5.9$ & $32.6 \pm 5.1$ \\
\hline S-BP (mmHg) & $145.5 \pm 17.3$ & $141.9 \pm 20.7$ & $144.9 \pm 16.1$ & $142.0 \pm 21.3$ & $144.5 \pm 19.5$ & $141.6 \pm 20.1$ \\
\hline T-cho (mg/dl) & $221.4 \pm 41.0$ & $227.2 \pm 42.7$ & $226.3 \pm 35.4$ & $225.2 \pm 45.1$ & $225.0 \pm 34.8$ & $226.1 \pm 47.9$ \\
\hline $\mathrm{TG}(\mathrm{mg} / \mathrm{dl})$ & $102.1 \pm 44.9$ & $126.0 \pm 82.3$ & $117.9 \pm 64.4$ & $119.9 \pm 78.8$ & $105.1 \pm 54.8$ & $131.6 \pm 86.3$ \\
\hline $\mathrm{FBS}(\mathrm{mg} / \mathrm{dl})$ & $101.4 \pm 12.1$ & $97.1 \pm 14.8$ & $97.4 \pm 12.0$ & $98.7 \pm 14.6$ & $97.7 \pm 1.9$ & $98.8 \pm 1.8$ \\
\hline $\mathrm{VO}_{2} \max (\mathrm{ml} / \mathrm{kg} / \mathrm{min})$ & $23.7 \pm 3.5$ & $26.0 \pm 3.8^{* *}$ & $25.3 \pm 4.0$ & $25.4 \pm 3.7$ & $25.2 \pm 4.0$ & $25.5 \pm 3.7$ \\
\hline Daily number of steps (step) & $76828.0 \pm 3096.9$ & $8854.5 \pm 3343.7$ & $8664.0 \pm 280.1$ & $8455.2 \pm 3530.1$ & $8531.3 \pm 2855.9$ & $8513.2 \pm 3676.3$ \\
\hline Dietary caloric intake (Kcal) & $1845.2 \pm 527.7$ & $2012.3 \pm 403.9$ & $1892.0 \pm 403.0$ & $1999.8 \pm 463.8$ & $1951.0 \pm 381.4$ & $1978.2 \pm 499.2$ \\
\hline
\end{tabular}

Each parameters were compared between the two groups (presence or absence) respectively by Mann-Whitney U-test. Statistical significance is shown to be asterisk, ${ }^{* *} p<0.01$.

た。運動指導は，運動分のエネルギー消費量を 週単位で網羅する有酸素運動中心のトレーニン グメニューを作成し当施設で実施することと， 日常生活活動の増加を促すため, カロリーカウ ンター (SUZUKEN 社製 E-style $\left.{ }^{\circledR}\right)$ を装着し歩 数の記録を指導した。栄養指導は, 自己記入式 の 3 日間食事調査票 12）を用いて, 総摂取カロ リーを算出した。また食品群の過不足を分析 し，摂取制限をする具体的な食品や量などを指 導した。これらの指導内容実施の確認と修正指 導を月 1 回の面談で行った。

自覚症状の問診調查は, 運動器系症状に関わ る 3 項目（膝が痛い, 腰が痛い, 肩こりまたは
首筋がはる), とし，自覚症状の有無について は, 問診票記入時付近の $1 \sim 2$ 力月間で自覚し た症状を「あり」「なし」として，問診票に記入 してもらった。

検査項目は介入開始時および 6 力月後に以下 の項目の計測を行った。

検查項目として年齢, 身長, 体重, BMI, 体 脂肪量〔身体密度を水中体重科量法より測定し, Brozek ら 2) の体脂肪推定式より算出了, 収縮期 および拡張期血圧〔自動血圧計（エイアンドデ イ社製 TM2655）を用いて座位安静にて測定〕, 最大酸素摂取量〔トレッドミル装置（酒井医療 器社製スーパートレッドミル $\left.{ }^{\circledR}\right)$ を用いて, 運 

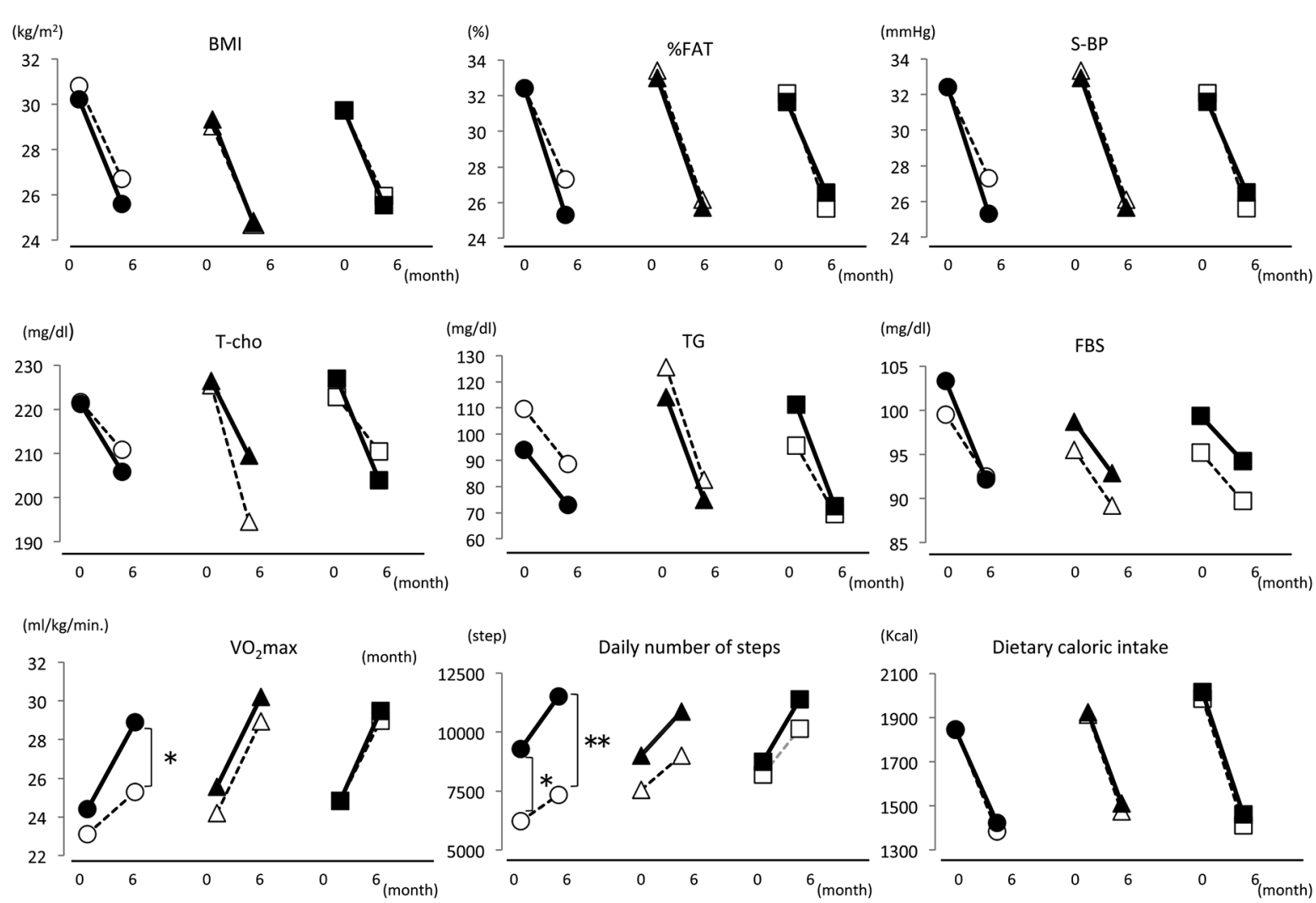

Fig.1 Changes of test parameters before and after intervention in subjects complaining of Knee pain, Low back pain, Neck stiffness.

Each parameters were compared between the two groups ("improved" or "no change") by Mann-Whitney U-test before and after intervention. Statistical significance is shown to be asterisk, ${ }^{*} p<0.05,{ }^{* *} p<0.01$.

OKnee pain improved $\bigcirc$ Knee pain no change $\boldsymbol{\Delta}$ Low back pain improved $\triangle$ Low back pain no change

$\square$ Neck stiffness improved $\square$ Neck stiffness no change.

動中の呼気ガス分析を呼気ガス代謝測定装置 （フクダ産業社製 Oxycon-Pro ${ }^{\circledR}$ ）を用いて呼吸 商 1.04 を最大酸素摂取量 $(\mathrm{ml} / \mathrm{kg} / \mathrm{min})$ として 計測〕，血液検查〔T-cho, TG，空腹時血糖 值〕，1 日当たりの歩数〔カロリーカウンターに て毎月の最後の 1 週間を平均し，1 日あたりの 歩数を算出]，食事摂取カロリー〔3 日間食事調 查票から総摂取カロリーを算出]を 6 カ月の減 量介入開始時および終了時で測定し，腰痛，膝 痛，肩こりの各症状について介入前の症状あり 群，なし群で比較検討を行った。また症状あり 群については，減量介入後に該当症状がなく
なったものを改善群, 症状が残存していたもの を不変群とし，減量介入前後における測定項目 の比較検討を行った。統計解析には統計プログ ラムパッケージ PASW ${ }^{\circledR}$ を用い, Man-whiteny U 検定を行った。

\section{結 果}

対象者における運動器系自覚症状の頻度 は，肩こり (46.6\%) が最も高く, 続いて腰痛 


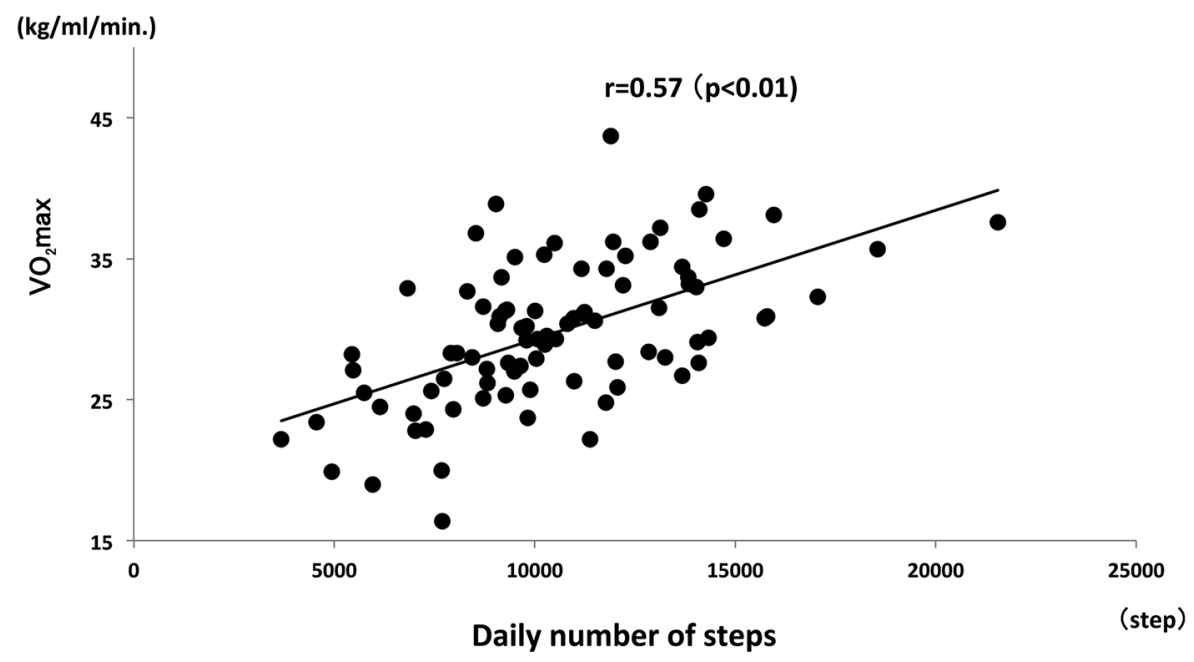

Fig.2 Correlation between daily number of steps and $\mathrm{VO}_{2}$ max.

(31.8\%), 膝痛 $(28.4 \%)$ の順であった。肩こり， 腰痛ではいずれのパラメータでも両群間で統計 学的有意差はみられなかったものの, 膝痛で は, 症状あり群はなし群に比べ, 年齢が有意に 高く $(p=0.007)$ ，また持久力の指標である最大酸 素摂取量が有意に低かった $(p=0.004)$ (Table 1$)$ 。 ベースラインに扔いて各運動器系自覚症状あ り群では, 6 カ月の減量プログラム介入後いず れのパラメータも有意な変化が認められた。ま たこのうち減量介入後症状改善群と不変群にお いても, 肩こりと腰痛ではいずれのパラメー夕 も統計学的有意差は認められなかった (Fig.1)。 一方膝痛では, 減量介入前では状改善群の 1 日 あたりの歩数が不変群に比し有意に多かった $(p=0.012)$ 。また減量介入後では改善群の最大 酸素摂取量は不変群に比し有意に高くなり $(p=0.047), 1$ 日あたりの歩数も更に有意に増 加した $(p=0.002)($ Fig.1)。膝痛の改善要因に関 与していた最大酸素摂取量と他の項目値との関 連を相関分析すると, 最大酸素摂取量は万歩計 の歩数と有意な正の相関を示した $(r=0.57$, $p<0.001)$ (Fig.2)。

\begin{tabular}{l} 
考 察 \\
\hline
\end{tabular}

過体重・肥満がリスク要因となる病態につい ての研究は多いが, 有訴率の高い運動器疼痛症 状について, 過体重の病態の中でも何が症状へ 関与しているか調查した報告は少ない。本研究 では調查対象を過体重者に限定し, 実際に運動 器症状を有するものと, 有しないものの各種パ ラメー夕を比較することでそれぞれの症状に関 与する因子の検出を試みた。その結果, 腰痛, 肩こりに関連する因子は見いだせなかったもの の, 膝痛に関しては, 症状あり・なし群の比較 で, 年齢および最大酸素摂取量に有意差が認め られ，持久力の低下が膝痛の関連因子であるこ とが示唆された。さらに実際の減量介入では, 最大酸素摂取量を増加の程度が膝痛を改善させ る因子一つであることが示唆された。

リウマチや特異性関節炎など以外で明確な疾 病に起因しない膝痛の最大の原因として滕 $\mathrm{OA}$ が知られている。本病態がもたらす痛みなどの 機能障害はレントゲンによる画像検査に反映さ 
れにくいことが知られているが，近年， 20 年 間の長期的縦断調查に扔いて, 膝痛有訴率の増 加要因として, レントゲン変化の関与はそしい 一方で, 加齢と過体重は独立した有意なリスク 要因であることが米国の研究から報告されてい る21）加龄が膝痛のリスク因子であることは, 本研究の過体重者においても, 膝痛症状の有無 により年齢の有意差がみられた結果から矛盾し ないものであるといえる。一方，過体重・肥満 と膝痛には強い関連があると考えられる一方 で，肥満解消と滕痛の予後については様々な報 告 $6,18,19,22)$ がある。例えば，消化管の肥満外科 手術により, 過体重・肥満改善に伴い膝痛の改 善をもたらす22）といったものの他に，運動療 法を介入せず食事療法のみで減量した場合は, 膝痛の改善が劣るという報告 ${ }^{19)}$ などがみられ るが，いずれも減量自体が重要な因子であると 報告されている。一方，実際に本研究に打ける 膝痛有訴者への減量介入において, 改善群, 不 変群の減量結果に有意な差はみられず，膝痛改 善の要因として単に減量自体に効果があるとは 言い難い結果であった。減量自体の除痛効果は これまでの様々な報告からも周知のものといえ るが, 本研究において減量の除痛効果を証明で きなかった原因として，本研究では膝痛の評価 について自覚症状そのものについてあり・なし のみを調查するに留まって抢り，その重症度を スコア化（例えば VAS や JKOM スコア）した 調查でないことが問題点としてあげられる。

膝痛の最大の要因とされる滕 OAのガイド ライン10)において, 有酸素運動は, 抵抗運動 と並んで最も推奖される非薬物治療法としての 高いエビデンス 3) を有しているが, 特に過体 重・肥満者に特化した滕痛調查において, 有酸 素運動能力の指標となる最大酸素摂取量につい て報告したものはない。今回の調查では, 介入
前の状態において膝痛あり群・なし群で最大酸 素摂取量に有意差が認められており，また介入 前の滕痛有訴者においては, 減量後の症状改善 群では不変群を比較すると, 最大酸素摂取量に 有意差が認められた。本結果は, 最大酸素摂取 量の増加の程度が膝痛改善に対する因子である ことを示唆する結果であるといえる。また滕症 状改善群では, 減量介入後最大酸素摂取量と同 時に万歩計による歩数自体も増加していたこと から, 減量の過程において, 食事と共に有酸素 運動能力の獲得につながるような身体活動量の 増加が, 膝痛症状改善に重要であることが示唆 された。

一方，腰痛に関しては介入前の状態からも， 症状あり群と，なし群の病態に結びつくこれら のパラメータを見出すことができず，隇量によ る症状改善率は, 今回調查した 3 症状の中で最 も高かったにもかかわらず, 改善群と不変群で も改善効果を示すデー夕を見出すことはできな かった。近年の報告から, 腰痛の原因は非常に 複雑であり，単に身体的な問題だけではなく， 心理社会要因まで含めた評価が必要と言及され ている 16)。このような腰痛自体の複雑さに加 え, BMI の増加と腰痛の関連性を見いだせな いとする報告 ${ }^{8)}$ もられることから, 今回改善 群と不変群で減量結果や他の検査項目に差がな かったことは, 過体重・肥満者の腰痛改善の要 因として, 物理的な質量因子の変化よりも, 今 回計測できていない炎症性マーカーや，身体機 能の変化, 心理社会因子の変化の検討が課題と して残る。

また，肩こりに関しては，日本に扔ける国民 有訴率の最も高い症状 9）であるが，「肩こり」 という言葉自体が日本独特の言語であり, 他国 との比較を行う場合は，しばしば䅡部痛 (Neck pain）などの言葉に置き換えられている11,14)。 
過体重・肥満やメタボリック症候群と頚部痛の 関連を調査した報告はいくつかみられてお り 15,17,22)，いずれもこれらの状態は陑部痛のリ スク因子であると報告されているものの, 澒部 痛への詳細な要因については明らかにされてい ない。本研究では, 過体重・肥満者で症状あり・ なしでの比較により，痛みの病態の検出を試み たが，腰痛同様に有意な所見を見出すことはで きなかった。本結果は, 過体重・肥満者におけ る肩こりや腰痛症状の要因特定分析には調查不 十分であることを示唆しており，今後さらに心 理社会背景まで含めた, より詳細な項目の分析 が必要と考えられる。

\section{結語}

過体重・肥満者に対して 6 カ月の減量プログ ラムを実施し，対象者の腰痛・肩こり・膝痛の自 覚症状有訴者の特徵を様々なパラメーターを用 いて調查した。その結果, 減量開始前の時点に おいて症状あり・なしの群間で, 膝痛のみ年齢 と最大酸素摂取量に有意差を認めた。さらに膝 痛あり群については, 減量介入後, 症状改善群 において症状不変群との間に最大酸素攝取量の 有意差が認められた。また対象者全体でみると 最大酸素摂取量は 1 日歩数と正の相関を示し た。本結果より過体重・肥満者の膝の痛みの改 善には, 減量のみでなく, より高い持久力向上 につながる活動量の増加が重要であることが示 唆された。

\section{文 献}

1) Andersen, R.E., Crespo, C.J., Bartlett, S.T., Bathon, J.M., Fontaine, KR., Relationship between body weight gain and significant knee, hip, and back pain in older Americans, Obes. Res., 11 (2003) 1159-1162.

2) Brozek, J., Grande, F., Anderson, J.T., Keys, A., Densitometric analysis of body composition: Revison of some quantitative assumptions, Ann. N.Y. Acad. Sci., 110 (1963) 113-1140.

3) Ettinger, W.H. Jr., Burns, R., Messier, S.P., Applegate, W., Rejeski, W.J., Morgan, T., Shumaker, S., Berry, M.J., Otoole, M., Monu, J., Craven, T., A randomized trial comparing aerobic exercise and resistance exercise with a health education program in older adults with knee osteoarthritis, The Fitness Arthritis and Seniors Trial(FAST), JAMA, 277 (1997)25-31.

4) Ferreira, P.H., Beckenkamp, P., Maner, C.G., Hopper, J.L., Ferreira, M.L., Nature or nurture in low back pain ? Results of a systematic review of studies based on twin samples, Eur. J. Pain, 17 (2013) 957-971.

5) Felson, D.T., Goggins, J., Niu, J., Zhang, Y., Hunter, D.J., The effect of body weight on progression of knee osteoarthritis is dependent on alignment, Arthritis Rheum., 50 (2004)39043909.

6) Felson, D.T., Zhang, Y., Anthony, J.M., Naimark, A., Andorson, J.J., Weight loss reduces the risk for symptomatic knee osteoarthritis in women. The Framingham Study, Ann. Intern. Med., 116(1992)535-539.

7) Grotle, M., Hagen, K.B., Nativing, B, Dahl, F.A., Kvien, T.K., Obesity and osteoarthritis in knee, hip and/or hand: an epidemiological study in the general population with 10 years follow-up, BMC Musculoskelet. Disord., 9 (2008) 132 .

8) Han, T.S., Schouten, J.S.A.G., Lean, M.E.J., Seidell, J.C., The prevalence of low back pain and associations with body fatness, fat distribution and height, Int. J. Obes. Relat. Metab. Disord., 21 (1997)600-607.

9) Health and Welfare Statistics Association (Japanese) Annual Statistical Report of National Health Conditions, (2010/2011) pp72-73.

10) Hochberg, M.C., Altman, R.D., Applil, K.T., Benkhalti, M., Guyatt, G., Mcgowan, J., Towheed, T., Welch, V., Wells, G., Tugwell, D., American College of Rheumatology 2012 recommendations for the use of nonpharmacologic and pharmacologic therapies in osteo- 
arthritis of the hand, hip, and knee, Arthritis. Care Res.(Hoboken), 64(2012) 465-474.

11) Iizuka, Y., Shinozaki, T., Kobayashi, T., Tsutsumi, S., Osawa, T., Ara, T., Iizuka, H., Takagishi, K., Characteristics of neck and shoulder pain (called katakori in Japanese) among members of the nursing staff, J. Orthop. Sci., 17 (2012) 46-50.

12) Imai, T., Sakai, S., Mori, K., Ando, F., Niino, N., Simokata, H., Nutritional assessments of 3-day dietary records in National Institute for Longevity Sciences - Longitudinal Study of Aging(NILS-LSA), J. Epidemiol., 10 (suppl) (2000) S70-76.

13) Janke, E.A., Collins, A., Kozak, A.T., Overview of the relationship between pain and obesity: What do we know? Where do we go next?, J. Rehabil. Res. Dev., 44(2007)245-262.

14) Jimbo, S., Atsuta, Y., Kobayashi, T., Matsuno, T., Effects of dry needling at tender points for neck pain (Japanese: katakori): near-infrared spectroscopy for monitoring muscular oxygenation of the trapezius, J. Orthop. Sci., 13(2008) $101-106$.

15) Kääriä, S., Laaksonen, M., Rahkonen, O., Lahelma, E., Leino-Arjas, P., Risk factors of chronic neck pain: a prospective study among middle-aged employees, Eur. J. Pain, 16 (2012) 911-920.

16) Kikuchi, S., New concept for backache: biopsychosocial pain syndrome, Eur. Spine J., 17 (2008) 421-427.

17) Mäntyselkä, P., Kautiainen, H., Vanhala, M., Prevalence of neck pain in subjects with metabolic syndrome - a cross-sectional population - based study, BMC Musculoskelet. Disord., 30 (2010) 171 .

18) McGoey, B.V., Deltel, M., Saplys, R.F., Kliman, M., Effect of weight loss on musculoskeletal pain in the morbidly obese, Bone Joint Surg. Br., 72(1990)322-323.

19) Messier, S.P., Loeser, R.F., Miller, G.D., Morgan, T.M., Rejeski, W.J., Sevick, M.A., Ettinger, W.H. Jr., Panor, M., Williamson, J.D., Exercise and dietary weight loss in overweight and obese older adults with knee osteoarthritis: the Arthritis, Diet, and Activity Promotion Trial, Arthritis Rheum., 50(2004) 1501-1510.

20) Miscio, G., Guastamacchia, G., Brunani, A., Priano, L., Baudo, S., Mauro, A., Obesity and peripheral neuropathy risk: a dangerous liaison, J. Peripher. Nerv. Syst., 10 (2005) 354-358.
21) Nguyen, U.S.T.D., Zhang, Y., Zhu, Y., Niu, J., Zhang, B., Felson, D.T., Increasing prevalence of knee pain and symptomatic knee osteoarthritis: survey and cohort data, Ann. Intern. Med., 155(2011)725-732.

22) Peltonen, M., Lindroos, A.K., Torgerson, J.S., Musculoskeletal pain in the obese: a comparison with a general population and long-term changes after conventional and surgical obesity treatment, Pain, 104(2003)549-557.

23) Prospective Studies Collaboration, Body-mass index and cause-specific mortality in 900000 adults: collaborative analyses of 57 prospective studies, Lancet, 373 (2009) 1083-1096.

24) Ray, L., Lipton, R.B., Zimmerman, M.E., Katz, M.J., Derby, C.A., Mechanisms of association between obesity and chronic pain in the elderly, Pain, 152(2011) 53-59.

25) Rodacki, A.L., Fowler, N.E., Provensi, C.L.G., Rodacki, C.L.N., Dezan, V.H., Body mass as a factor in stature change, Clin. Biomech., 20 (2005) 799-805.

26) Sharma, L., Lou, C., Cahue, S., Dunlop, D.D., The mechanism of the effect of obesity in knee osteoarthritis: the mediating role of malalignment, Arthritis. Rheum., 43 (2000) 568-575.

27) Stallings, S.P., Kasdan, M.L., Soergel, T.M., Corwin, H.M., A case-control study of obesity as a risk factor for carpal tunnel syndrome in a population of 600 patients presenting for independent medical examination, J. Hand Surg. Am., 22(1997)211-215.

28) Tesfaye, S., Chaturedi, N., Eaton, S.E.M., Ward, J.D., Manes, C., Ionescu-Tirgoviste, C., Witte, D.R., Fuller, J.H., Vascular risk factors and diabetic neuropathy, N. Engl. J. Med., 352 (2005) 341-350.

29) Whitmer, R.A., Gustafson, D.R., BarrettConnor, E., Haan, M.N., Gunderson, E.P., Yaffe, K., Central obesity and increased risk of dementia more than three decades later, Neurology 71 (2008) 1057-1064.

\footnotetext{
Address for correspondence: Tomomi Hasegawa Institute of Physical Fitness, Sports Medicine and Rehabilitation, School of Medicine, Aichi Medical University

1-1 Yazako Karimata, Nagakute, Aichi 480-1195, Japan

Tel: 0561-61-1809 / Fax : 0561-63-3563

E-mail: tommyh627@gmail.com
} 